\title{
Lacks and Problems Encountered in a Military English Communication Course
}

\author{
Manjola Likaj \\ Foreign Languages Centre, at the Academy of Armed Forces, \\ Training and Doctrine Command, Tirana, Albania
}

\section{Doi:10.5901/mjss.2013.v4n11p516}

\begin{abstract}
The paper focuses on the lacks and problems encountered by teachers and learners of a military English course on communication and gives recommendations on how to overcome them. After these problems have been identified, it relies on all parties involved in the teaching process to contribute in reducing them, i.e. the syllabus design board, the teachers and the military students. One of the most apparent issues is related with the lack of a specific syllabus design for military English communication. Thus the teacher's job becomes quite a challenge. What is more, some teachers are not well-trained in teaching military English communication, so they are not familiar with the subject matter and do not master the content. Moreover, the officers who attend a communicative military course have different English competence, starting from low levels to advanced one, so the teacher has to select and use appropriate communicative tasks according to the students' language knowledge. Besides that, there are not many military course books on communication available, so it is teacher's responsibility to find the right materials and to make use of all available English resources. In fact, another fundamental aspect concerning a military English communicative course has to do with students' eagerness to learn English. In conclusion, knowing all the weaknesses and difficulties that a teacher may face while teaching English communication in a military group helps the teacher to focus, be committed and accomplish his teaching mission by providing a class of competent communicators.
\end{abstract}

\section{Introduction}

Nowadays the importance of English language in the Albanian Armed Forces is a crucial, immediate and fundamental issue. Teaching English to military personnel is set as a major priority in the academic curricula of the Academy of the Albanian Armed Forces. With the collapse of the Communist regime in Albania in 1990 a sudden interest emerged in English language, as a globally spoken language, part of which was also military English. Albanian Army was open to cooperate and pool resources with its international partners worldwide, especially with The North Atlantic Treaty Organisation (NATO). New missions and strategies meant re-examining Albanian military structure and goals, among which military English had a significant role.

After Albania joined NATO in 2009, new objectives were set and new standards had to be met. Mastery of English, as the first NATO language, became one of the top priorities in Albanian Armed Forces. Speaking English effectively is vital to a professional officer who intends to enhance his professional and academic development and who wants to pursue a career path in the Albanian Army. At present, Albanian military troops operate in accordance with the Alliance needs. Only through effective communication will they be able to perform a successful duty. Speaking English is essential to the military personnel who participate in international organisations, in peacekeeping operations and partake in various trainings abroad. Therefore, it is quite necessary to provide communicative courses in military English according to the officers' needs. Only through such courses will the military personnel be able to accomplish their missions successfully and represent our country proudly.

Teaching English to military personnel has always been a major factor in the academic curricula of the Academy of the Armed Forces in Albania. Above all language skills, speaking is the one which dominates widely. The introduction of Communicative Language Teaching Approach changed the way we teach speaking to our students dramatically. Specific English courses are provided by the Foreign Languages Centre according to the officers' needs.

\section{Literature Review}

Teaching English communicative competence to officers requires high professionalism as a teacher and mastery of language content, thus a teacher of a military English communicative course is dual-hated. He or she should be openminded to new ways of teaching, he should set clear and achievable goals in his course, he should consider himself a 
co-learner and part of the class, and finally he or she should develop a specific communicative curriculum according to students' needs and time-constraints. Since the focus of the English communication course is on the process of military English acquisition, achievement and success in the major goals are measured in terms of 'the purposes for which people are learning language and the kinds of language performance that are necessary to meet those purposes' Wilkins, (1976).

Teaching communicative competence to adult learners, especially to military students, is not easy. First of all, the teacher who is responsible for teaching English communication should have a clear idea of what communicative competence is. According to Richards (2006), communicative competence includes the following aspects of language knowledge:

- Knowing how to use language for a range of different purposes and functions;

- Knowing how to vary our use of language according to the setting and the participants (e.g., knowing when to use formal and informal speech or when to use language appropriately for written as opposed to spoken communication);

- Knowing how to produce and understand different types of texts (e.g., narratives, reports, interviews, conversations);

- Knowing how to maintain communication despite having limitations in one's language knowledge (e.g., through using different kinds of communication strategies).

The above aspects of communicative competence are applied in military communication as well. The first aspect requires our students to be aware of military English language use according to specific purposes and functions. For instance, they are asked to be involved in real-life situations in which they inquire logistic support in a civilian emergency. In this case, they practice the right terminology in order to fulfil their purpose. The second aspect deals with use of military language in accordance with the communicative situation and the participants i.e. they will speak friendly to a colleague when they meet in a mess hall, and formally to the same person when they meet in an office. The third one deals with understanding different types of text and military language offers quite a large range of texts starting with memos, different kinds of reports, orders, directives, presentations, briefings etc. The last aspect consists of exchanging and maintaining communication despite the deficiencies they have in English language knowledge. In such a situation conveying the message is the most important issue, which means being able to give and get the message from the sender, despite all the grammatical and structural mistakes. Thus the communication is meaningful, interacting and engaging. In this kind of communication the students use gestures and non-verbal language for the unknown words. To sum up, all these components comprise what is known as communicative competence in general English and the same components are part of the communicative competence in the military English as well.

Furthermore, after identification of communicative competence components, the teacher should develop a communicative syllabus and an effective curriculum. Designing a military English communicative curriculum is quite a challenge due to the scope of subject content and work- related goals to be met during the course. In the Foreign Language Centre of the Academy of the Armed Forces military English language curricula are designed, but not specifically communicative ones. This is considered a major problem faced by communicative course teachers. So, it relies on the teacher to find the right materials and to plan their use properly. These curricula should be tailored to military student needs, such as those who are deployed in peacekeeping missions, those who are assigned to represent Albania in NATO organization, to others are prepared to be part of an international team of nurses who serve in Afghanistan as well as some others who perform their duty as mentors in Operational Mentor Liaison Team (OMLT) in the same country. Therefore, we should design a communicative curriculum with speaking tasks that meet learners' needs. Learners' communicative needs provide a framework for elaborating program goals with regard to functional competence. (Savignon, 2002).

According to Littlewood (2002), the following issue should be taken into consideration: "a communicative view of language can help the teacher to make the linguistic content of a course more relevant to learners' needs; and how "a communicative view of language can provide the teacher with alternative ways of organizing this content into teaching units (e.g. lessons or sequences of lessons). First of all, we should specify the goals and the objective that we want to achieve in the communicative course (Nunan, 2001). A military communication course should provide practice in effective speaking skills in a military environment. Thus, the content is categorized and organized according to the deadline of the course. Finally, the teacher should reflect on the specification of terminology, functions, grammatical items, military topics, notions etc. So, as Littlewood (2002) states, the teacher should have a checklist for predicting communicative needs. The mentioned checklist helps the teacher to answer certain questions about the situations that $a$ learner might encounter, language activities in which he is going to be engaged, the most useful functions of language 
and the most essential topics and notions.

Additionally, finding the right materials from all available English resources is undoubtedly essential when it comes to curricula design. They can make use of general English methods, authentic materials taken from English books, newspapers, magazines, academic journals, internet etc. All these speaking materials should be relevant to the military environment, i.e. army manuals, real-life situations from the battlefield or exercise, military expression and acronyms from NATO documents etc. These materials, authentic or tailored by the teacher, will provide the students the proper language content. All too often, teachers of a communicative course have to evaluate, design and develop the military English communicative tasks themselves due to the lack of military language materials. The teacher should be very selective with the wide range of teaching materials that he or she practices in the classroom. Consequently, he or she should carefully take into account the communicative tasks consistent with the language knowledge of the students, involving role-plays, dialogues, debates, puzzles, jigsaw etc. He or she evaluates if the task is appropriate for his or her class and if it works properly for his teaching goals. As Hyland (2006) stated 'from rights and needs assessments a systematic course plan has to be developed by selecting and sequencing the content and tasks that will lead to desired learning outcomes'.

\section{Methodology}

The methodology of the research article deals with the way this study is conducted. The paper is concerned with the difficulty faced by teachers in finding, designing and using communicative class in a military English communication course, students' interest in doing these speaking tasks and problems encountered by both teachers and students in practicing them.

In this part of the article the research design will be described, the participants, data collection methods, the procedure that was applied during this mini-research and finally data analyses technique used by the researcher.

\subsection{Type of research}

This research employs observation and survey methods. The observation method makes use of the researcher' experience as a military English teacher, whereas the use of questionnaires provides the information given by the participants of the study. All data is collected to find out the difficulties and problems that military English teachers face in finding, designing and using communicative tasks and to give recommendations on how to overcome this problem. The research is conducted to collect information on the following aspect:

- The difficulties of finding and designing communicative military tasks in teaching speaking to military students.

- The difficulties of practicing communicative activities faced by teachers and students of a military communication course.

- The military students' attitude toward communicative tasks.

\subsection{The participants}

The research was carried out in the Foreign Languages Centre (FLC), at the Academy of the Armed Forces, in Tirana, Albania. Currently, the FLC runs five English language proficiency courses according to specific Standardized Agreement (STANAG 6001) levels, which is a NATO agreement among member countries for an acceptable linguistic competence that enables cooperation. They consist of 70 military students. The study was organized only in three groups, in a level 3 333 group, which refers to an advanced level, and in two other 3232 groups, equal to upper-intermediate level in English. Most of the students are military, who work in the Albanian Armed Forces, and only a few are civilians who work at the Ministry of Defence. The total number of students who participated in this study was 31 respondents, who came from the three respective groups mentioned above. The table below presents the relevant information gathered by the student respondents regarding the number of students involved, their gender and the number of years they have studied English:

Table 1. Students' demographic information.

\begin{tabular}{|c|c|c|c|c|c|c|c|}
\hline Group & Group & \multicolumn{2}{|c|}{ Gender } & \multicolumn{4}{c|}{ Average years in English learning } \\
\cline { 3 - 7 } Name & Size & Female & Male & $0-3$ & $3-7$ & $7-10$ & Over 10 \\
\hline
\end{tabular}




\begin{tabular}{|l|c|c|c|c|c|c|c|}
\hline 3232 & 9 & 3 & 6 & 4 & 4 & 1 & - \\
\hline 3232 & 8 & 1 & 7 & 3 & 4 & - & 1 \\
\hline 3333 & 14 & 6 & 8 & 7 & 5 & 1 & - \\
\hline
\end{tabular}

Besides the military students, the focus of this study was on the military English teachers too. The questionnaire was given to 14 military English teachers who teach the respondents of the questionnaires. They are from the age of 24 to 59 , most of them have more than 10 years in teaching military English, and the youngest one has at least two years in this profession. The following table will give the necessary data on the teaching experience of military English teachers and their gender:

Table 2. Teachers' demographic information

\begin{tabular}{|c|c|c|c|c|c|c|}
\hline \multirow{2}{*}{ Group Name } & Group & \multicolumn{2}{|c|}{ Gender } & \multicolumn{3}{|c|}{ Average years in teaching English } \\
\cline { 3 - 7 } & Size & Female & Male & $0-5$ & $5-10$ & Over 10 \\
\hline $\begin{array}{c}\text { Military English } \\
\text { teachers }\end{array}$ & 14 & 10 & 4 & 1 & 6 & 7 \\
\hline
\end{tabular}

\subsection{Data collection method}

The first method used in this study was the observation. The researcher as a military English teacher observed carefully every detail that is related with the topic of this paper. So, the researcher took into consideration the selection of the communicative tasks, their evaluation, design and finally their practice in a military English class. She wrote down the problems, difficulties and lacks she dealt with during her study.

The second method employed was the survey questionnaire. Two kinds of questionnaires were used, one for the military students and the other one for the military English teachers.

Both questionnaires were written in Albanian and they were composed of 2 sections:

- Section 1: The respondents were asked about their gender, education and how long they had been learning/ teaching military English

- Section 2: Each questionnaire had 8 military communicative tasks which were the same for both teachers and students. Three specific questions were asked to each group of respondents (teachers, students) regarding these 8 speaking tasks:

1. The frequency of use of the military communicative tasks (both to military students and teachers);

2. The difficulty they face in using these military communicative tasks (both to military students and teachers);

3. Teachers 'difficulty in finding and designing communicative tasks;

4. Students' interest in doing such communicative tasks.

\subsection{Data analysis:}

First of all, the collected data from the respondents were analysed and classified according to three specific question of the study. Therefore, the answers given to these three questions helped us to find out the answer of the main research question that has to do with difficulties in finding, deigning and using communicative tasks in teaching military communicative competence.

Secondly, the descriptive statistic method was used to process the information taken from the questionnaires. After that, the researcher analysed the data and rendered them in statistics according to each question made in the survey. Then, the received statistics were put in charts to illustrate and explain better the results of the study.

\section{Results taken from the questionnaires}

This part of the study gives the results and facts received from the research. After the data collection by military teachers and students the researcher found the following results: 


\subsection{The frequency of using military communicative tasks}

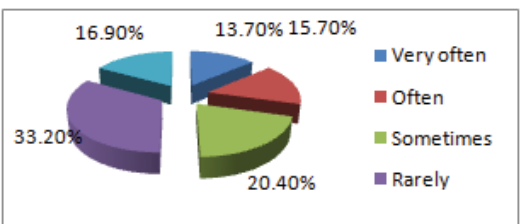

Figure 1: Students' answers about the frequency of use of the communicative tasks

At it can be seen from the above chart most of the military students, $33 \%$ of them, say that they rarely use communicative tasks. About $20 \%$ of them say that they sometimes use such tasks in their English course, whereas $17 \%$ of them say that they never apply such military communicative tasks. Approximately $15 \%$ of them say that they often deal with such communicative tasks and finally about $13 \%$ of them state that they use these tasks very often.

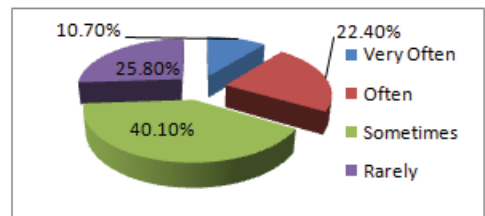

Figure 2. Teachers' answers about the frequency of use of the communicative tasks

According to Figure 2, most of the teachers, $40 \%$, sometimes use communicative tasks in their military English classes. $25 \%$ of them say that they rarely use them and about $22 \%$ of the teachers often apply these tasks. Only $10 \%$ of them use them very often and finally about $1 \%$ says that they never use them. So, military English communicative tasks are not employed very often in the courses provided by our centre.

\subsection{The difficulty in using military communicative tasks}

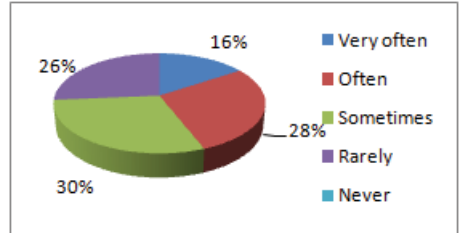

Figure 3. Students 'difficulty in using military communicative tasks.

It can be figured out in chart 3 , that $30 \%$ of the students sometimes face difficulty in using these communicative tasks, $28 \%$ often find them difficult, whereas $26 \%$ rarely encounter difficulty in doing them.16\% of the students very often face difficulty in carrying out such tasks and finally only $2 \%$ of the students never find it difficult in using CT.

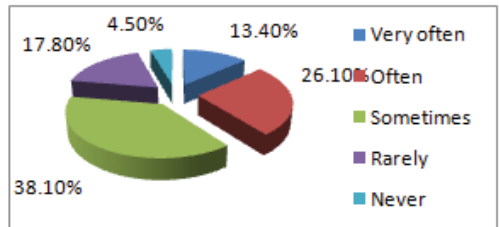

Figure 4.Teachers' difficulty in using military communicative tasks

It can be seen from the Figure 4, that most of the military English teachers, $38 \%$, sometimes encounter difficulty in applying communicative tasks in their classes. $26 \%$ of the teachers often find them difficult in using them in class, 
whereas $17 \%$ of them rarely face difficulty. $13.4 \%$ of the teachers say that they very often find it difficult to use them and only $4 \%$ of them never have problems in employing such tasks. As a result, military teachers and students consider the use of speaking tasks not very difficult and they are able to deal with them productively.

\subsection{The difficulty faced by military English teachers in finding and designing communicative tasks}

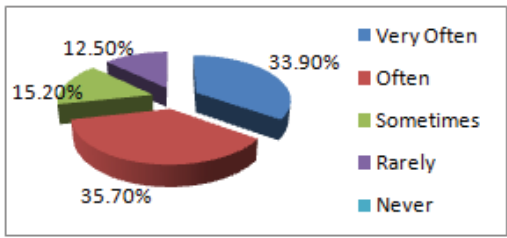

Figure 5. Military English teachers' difficulty in finding and designing communicative tasks

According to Figure $5,35 \%$ of the teachers say that they often encounter difficulty in finding and designing military communicative tasks. $33 \%$ of them state that they very often have problems in finding these tasks and $15 \%$ sometimes find it difficult to find and to prepare them. $12 \%$ of the teachers rarely have problems with such communicative materials and only $2 \%$ of them never find these tasks difficulty. Therefore, designing a communicative curriculum is considered a milestone in the teaching process.

\subsection{The interest of military students in using communicative tasks}

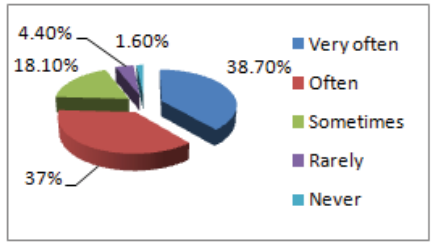

Figure 6. Students' interest in using military communicative tasks

Figure 6 , shows the interest of military students in doing communicative tasks. Most of them, $38 \%$ state that they would like to do these tasks more often. $37 \%$ of the students would like to use them often and $18 \%$ of them sometimes. Only 4 $\%$ would like to use them rarely and $1 \%$ never likes doing such tasks. To sum up, military students are in favour of practicing and using speaking tasks. Through practice of such tasks they are able to interact and acquire the target language easily.

\section{Recommendations and Conclusions}

Teaching English speaking to military students, cadets and officers is quite challenging to military English teachers. The teachers of military speaking courses deal with many problems and difficulties and it is their responsibility to overcome these obstacles in order to reach their major goal i.e. to enhance students' speaking skills. Communicative competence remains one of the most prominent skills of our students nowadays. Therefore, communicative tasks are really effective and indispensable in improving speaking skills of military students. As it was viewed in this paper, such communicative tasks are practiced in current English speaking courses in the Foreign Languages Centre, but their frequency of use is not at the required level. Most of the teachers sometimes use the communicative tasks in their classes, whereas from the students' point of view they state that they rarely practice them. According to the research results, the military students are very interested in using speaking tasks, which means they are highly motivated and willing to improve their speaking skills.

Regarding the difficulty encountered by teachers and students in using military English speaking tasks there are different views. Teachers prefer practicing such communicative activities but they often find it difficult to organize them properly. Preparing them is time consuming; managing teaching time and students in the class is quite a challenge; whereas for a part of the students these tasks are ineffective. However, all the teachers agree that the use of military 
speaking tasks in their courses improves English speaking among our military students.

Based on the facts of this study, it results that the military English teachers encounter lots of problems when it comes to speaking materials. So, it is suggested that a syllabus board be responsible for finding, evaluating and finally designing a curriculum on military English speaking course. At our FLC, different courses are organized according to the officers' needs, so specific curricula should be complied in accordance with the purpose of the course and time restrictions. Regarding speaking materials, the curricula design teachers should take into considerations certain resources and aspects:

- Most of the speaking materials should be authentic;

- They should make use of several resources, such as military academic books, military journals, newspapers, magazines, army manuals, military websites on internet etc.;

- A part of the materials need to be tailored according to the students' needs and language knowledge;

- Piloting is suggested before implementing out the new curricula. The design team can pilot the new curricula in different groups in order to find out in this way if the communicative tasks are effective or not, to see students interests in these tasks and teachers opinions as well;

- The speaking curricula should be flexible to the teachers, allowing them to arrange it in accordance with the specific language knowledge of their students;

- It should be possible for the teacher to up-date the speaking curriculum with any kind of speaking tasks they find useful and effective.

In conclusion, teaching speaking through communicative tasks is not unknown to our teachers; it is not a teaching technique that they are unaware of. In fact it is a matter of teaching perception, learning environment and nonconventional way of teaching. In addition, one of the most fundamental purposes of a military speaking course is to produce competent English communicators in the military field. If a military student is able to communicate in English fluently, accurately and in a comprehensive way in his working environment, then you as a teacher, have met the major objective of your speaking course. So, the teachers should have clear, realistic and achievable goals ahead of starting teaching speaking. Once these objectives are set, the teacher is able to design a productive and useful curriculum on the speaking course.

\section{References}

Hyland Ken, English for Academic Purposes, Routledge printed Company, 2006, pg. 81.

Littlewood William, Communicative Language Teaching, Cambridge University Press, 2002, pg 82.

Nunan David, Designing Tasks for the Communicative Class, Cambridge University Press, 2001.

Richards Jack C., Communicative Language Teaching Today, Cambridge University Press, 2006.

Savignon Sandra J., Communicative Language Teaching: Linguistic Theory and Classroom Practice, Yale University Press New Haven \& London, 2002, pg.4.

Wilkins, D., Notional syllabuses, Oxford University Press, 1976, pg. 13. 